\title{
Diferencias entre auditoría médica y la valoración de la aptitud médica para el trabajo
}

\author{
Differences between medical audit and medial fitness to work
}

\section{Sr. Editor:}

Con la finalidad de proteger y promover la seguridad y salud de los trabajadores, además de generar servicios de salud ocupacional adecuados, el Ministerio de Trabajo y Promoción del Empleo y, el Ministerio de Salud establecieron la responsabilidad de todos los empleadores para realizar los exámenes médicos ocupacionales a los trabajadores de todos los sectores económicos y de servicios,tanto en el ámbito privado, público, fuerzas armadas y policiales $(1,2)$.

Como responsable de los exámenes médicos ocupacionales, el Ministerio de Salud reconoce como médico ocupacional a los médicos con segunda especialidad en Medicina Ocupacional y Medio Ambiente o Medicina del Trabajo, al médico cirujano con Maestría en Salud Ocupacional o Maestría en Salud Ocupacional y Ambiental o Maestría en Medicina Ocupacional y Medio Ambiente, y al médico cirujano con estudio de Diplomado en Salud Ocupacional con un mínimo de 24 créditos académicos expedido por una escuela o Facultad de Medicina o de ciencias de la salud de una universidad pública o privada, hasta agosto del 2018 (3).

La vigilancia de la salud de los trabajadores es un componente inherente de cualquier gestión de salud en el lugar de trabajo, siendo la práctica más utilizada los exámenes médicos ocupacionales (4). Las evaluaciones médicas ocupacionales son actos médicos que permiten evaluar el estado de salud de los trabajadores (2,5). Uno de los propósitos principales de los exámenes médicos ocupacionales es la valoración de la aptitud del trabajador para ocupar un puesto de trabajo, con la intención de adaptar dicho puesto al trabajador $(4,5)$. Por lo tanto, la valoración de la aptitud médica para el trabajo constituye un acto médico, realizado bajo la responsabilidad absoluta del médico ocupacional $(2,4,6)$. La metodología para el desarrollo de los exámenes médicos ocupacionales comprende la elaboración de una historia o ficha médica, el examen físico, cuestionarios y pruebas biológicas en relación con los riesgos del ambiente laboral $(2,4)$. La información recopilada permitirá una línea de base para la vigilancia de la salud de los trabajadores.

Con la creación de los servicios de apoyo al médico ocupacional (SAMO) en el año 2011, se debieron implementar protocolos para la valoración de la aptitud médica para el trabajo basado en las exigencias de los puestos de trabajo y, además, lineamientos para la realización de los exámenes médicos ocupacionales, sin embargo, éstos aún no están desarrollados, requiriendoa la fecha, encontrar metodologías para la evaluación del acto médico a fin de establecer un proceso de retroalimentación y mejora continua (7). En la actualidad, los empleadores, como clientes dentro de un marco contractual, solicitan a los SAMO, el aseguramiento de la calidad de los exámenes médicos ocupacionales y proponen diversos instrumentos con este fin.

La auditoría médica es un proceso que evalúa el acto médico con el objetivo de mejorar la práctica médica, brindar educación continua y mejorar la calidad de la atención médica (5). En este caso, su propósito debería ser garantizar las competencias de los profesionales que desarrollan los exámenes médicos ocupacionales, determinar el uso eficiente de los recursos y lograr la satisfacción de los evaluados y de los empleadores. Por lo tanto, la acreditación de los servicios de apoyo al médico ocupacional deberían

\footnotetext{
Universidad Peruana Cayetano Heredia. Lima, Perú.

Universidad Católica Santa María. Arequipa, Perú.

Médico Ocupacional y Medio Ambiente; ${ }^{b}$ Médico Auditor
} 
estar enfocados en la evaluación del funcionamiento de éstos, para lograr que los usuarios reciban una atención de mejor calidad a través de evaluadores externos (8). En los próximos años, la certificación de sistemas de gestión de calidad en los SAMO, ayudará en la implementación de la mejora contiua de sus procesos, sin embargo, la verificación periódica, a través de auditorías periódicas, permitirá evaluar su desempeño y el logro de sus objetivos.

El propósito de esta comunicación es reflexionar sobre la superposición observada entre la auditoría médica y la práctica de la medicina ocupacional durante la realización de los exámenes médicos ocupacionales dentro de las SAMO. De esta manera, el análisis de la información recopilada durante los exámenes médicos ocupacionales permite realizar la valoración de la aptitud médica para el trabajo, siendo una responsabilidad del médico ocupacional acorde con los requisitos legales mientras que la calidad del acto médico y sus procesos, está dentro de los procesos de auditoría médica. También, es nuestra intención comunicar a las instituciones formadoras de auditores médicos sobre los aspectos conceptuales de la medicina ocupacional, para la debida estructuración del currículo. Por lo expuesto anteriormente, se trata de dos procesos que pueden complementarse pero que de ninguna manera se sobreponen.

\section{Raúl Gomero Cuadra ${ }^{1, a}$, Livia Calizaya de la Sota ${ }^{2, b}$}

\section{Correspondencia:}

Raúl Jesús Gomero Cuadra

Jr. Paseo de Aguas Mz D Lote 18, Urb. Portada del

Sol, La Molina, Lima, Perú.

Correo electrónico: Raul.gomero.c@gmail.com

\section{REFERENCIAS BIBLIOGRÁFICAS}

1. Congreso de la República. Ley de Seguridad y Salud en el Trabajo N 29783.Lima, Perú: Diario Oficial El Peruano; 26 de julio del 2011.

2. Ministerio de Salud. Documento Técnico Protocolos de Exámenes Médico Ocupacionales y Guías de Diagnóstico de los Exámenes Médicos obligatorios por Actividad. Resolución Ministerial $\mathrm{N}^{\circ}$ 3122011/MINSA. Lima, Perú: Dirección General de Salud Ambiental, Ministerio de Salud;2011.

3. Ministerio de Salud. Conforman Comisión Sectorial encargada de elaborar propuesta normativa que aborde lineamientos para el ejercicio de la medicina ocupacional en médicos cirujanos que no cuenten con segunda especialidad en Medicina del Trabajo o Medicina Ocupacional y Medio Ambiente, y emiten otras disposiciones. Resolución Ministerial N ${ }^{\circ} 763$ 2017/MINSA. Lima, Perú: Ministerio de Salud.

4. International Labour Office. Technical and ethical guidelines for workers' health surveillance, Ginebra: International Labour Office; 1998.

5. Gomero R. Propuesta para valorar aptitud en las evaluaciones médicas ocupacionales. Rev Med Hered. 2015; 26 (3):186-189.

6. Ministerio de Salud. Modifican el documento técnico "Protocolos de exámenes médicos ocupacionales y guías de diagnóstico de los exámenes médicos obligatorios por actividad". Resolución Ministerial Nº04-2014/MINSA. Lima, Perú: Dirección General de Salud Ambiental Ministerio de Salud; 2014.

7. Garaycochea V. Auditoría médica. Paediátrica. 2000; 3(1):27-28.

8. Ministerio de Salud.Acreditación deEstablecimientos. Lima, Perú: Comisión Nacional Sectorial de Acreditación. Ministerio de Salud; 2009.(Citado el 10 de febrero del 2018) Disponible enhttp://www. minsa.gob.pe/comisiones/acreditacion/acreditacion. asp

Recibido: 12/02/2018 